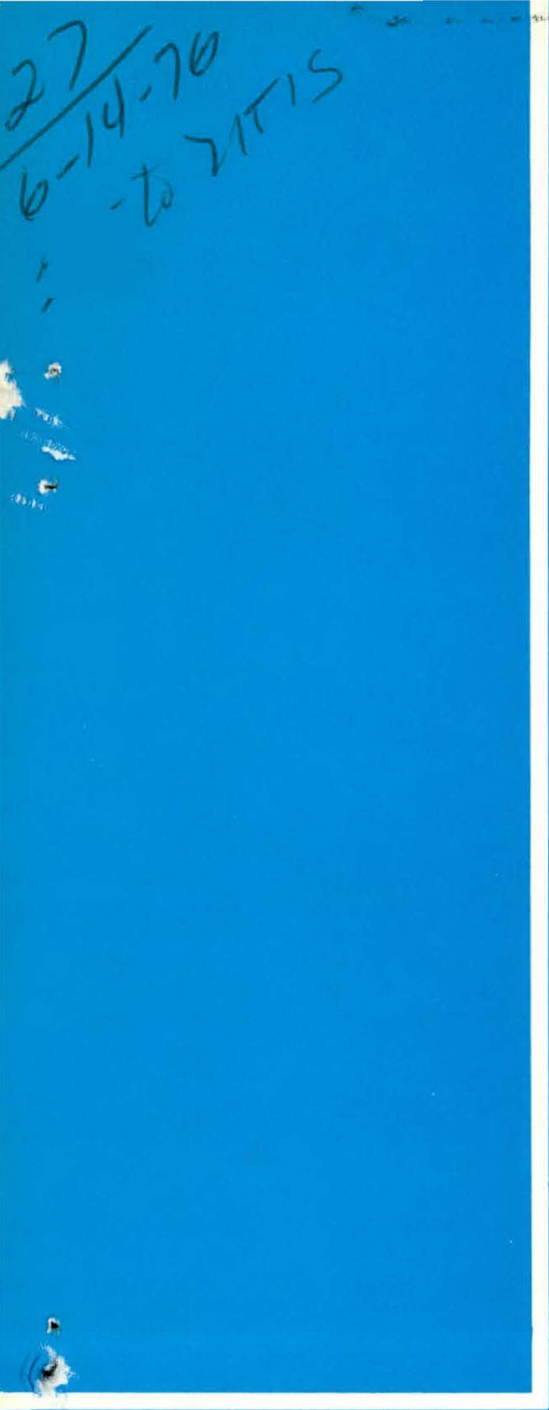

\title{
EPR and TNS
}

J. F. Clarke

\section{OAK RIDGE NATIONAL LABORATORY}

OPERATED BY UNION CARBIDE CORPORATION FOR THE ENERGY RESEARCH AND DEVELOPMENT ADMINISTRATION

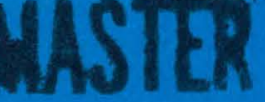




\section{DISCLAIMER}

This report was prepared as an account of work sponsored by an agency of the United States Government. Neither the United States Government nor any agency Thereof, nor any of their employees, makes any warranty, express or implied, or assumes any legal liability or responsibility for the accuracy, completeness, or usefulness of any information, apparatus, product, or process disclosed, or represents that its use would not infringe privately owned rights. Reference herein to any specific commercial product, process, or service by trade name, trademark, manufacturer, or otherwise does not necessarily constitute or imply its endorsement, recommendation, or favoring by the United States Government or any agency thereof. The views and opinions of authors expressed herein do not necessarily state or reflect those of the United States Government or any agency thereof. 


\section{DISCLAIMER}

Portions of this document may be illegible in electronic image products. Images are produced from the best available original document. 
Printed in the United States of America. Available from

National Technical Information Service

U.S. Department of Commerce

5285 Port Royal Road, Springfield, Virginia 22161

Price: Printed Copy \$3.50; Microfiche $\$ 2.25$

This report was prepared as an account of work sponsored by the United States Government. Neither the United States nor the Energy Research and Development Administration/United States Nuclear Regulatory Commission, nor any of their employees, nor any of their contractors, subcontractors, or their employees, makes any warranty, express or implied, or assumes any legal liability or responsibility for the accuracy, completeness or usefulness of any information, apparatus, product or process disclosed, or represents that its use would not infringe privately owned rights. 
ORNL/TM-5418

Contract No. W-7405-eng-26

EPR and TNS

J. F. Clarke

THERMONUCLEAR DIVISION

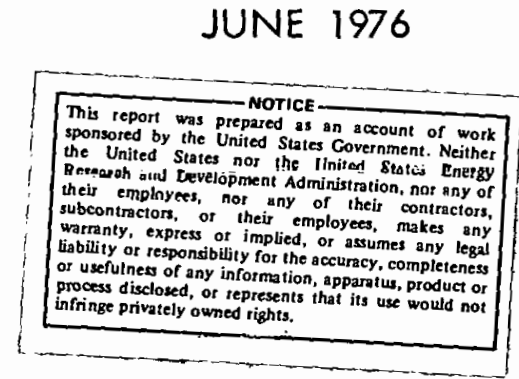

OAK RIDGE NATIONAL LABORATORY

Uak Ridge, Tennessee 37830

operated by

UNION CARBIDE CORPORATION

for the

ENERGY RESEARCH AND DEVELOPMENT ADMINISTRATION 


\author{
EPR and TNS: \\ J. F. Clarke
}

\title{
INTRODUCTION
}

During the preceding year a number of significant events have occurred which affect the future directions of the US Controlled Thermonuclear Research (CTR) program. An important consequence of this has been the recognition of the need for an intermediate CTR experiment, to be constructed before the first experimental power reactor (EPR). This device, called the next step (TNS), is the logical successor of the Technology Test Assembly with Plasma (TTAP) ${ }^{\prime}$ concept which has been pursued at ORNL for the past two years. The TNS has derived its basic function from the TTAP; namely, operational testing of EPR-relevant technologies and plasma control techniques. Recent successes in the confinement and heating of tokamak plasmas, together with advances in the theoretical understanding of highbeta equilibria, lead us to believe that the TNS can also anticipate many of the goals of the EPR in a cost-effective and timely manner. In this memo I shall discuss first the technical reasons which militate against the possibility of successful EPR construction of 1985, then the scientific and technological reasons which favor completion before 1985 of a TNS facility which would accomplish many of the purposes of the EPR.

\section{THE EPR}

\section{The Role of Beta and Aspect Ratio}

In the EPR designs so far completed ${ }^{2,3,4}$ the attainment of high beta has been heavily emphasized. This is because the fusion power which can be produced from a magnetic confinement system may be written ast

$$
\frac{d P}{d V}=1.5 \times 10^{30} B^{2} B^{4} \frac{\langle\sigma U\rangle}{T^{2}} E_{f}
$$

*The Next Step.

Units used in the equations of this paper are: length in $\mathrm{cm}$, magnetic fields in $T$, temperatures and energies in keV, and densities in particles/cc. 
The importance of achieving the highest possible value of $\beta$ follows from the difficulty of obtaining high magnetic fields. The strength of the magnetic field $B$ which can be utilized in a magnetic confinement device is constrained by technology. There is a limit on magnetic field for the two types of superconductor, $\mathrm{Nb}_{3} \mathrm{Sn}$ and $\mathrm{NbTi}$, which are available in commercial quantities. In addition, practical engineering considerations, and economic constraints based on the high price of the high-field superconductors, prevent us from utilizing fields much in excess of $120 \mathrm{kG}$ at the surface of the superconducting coil. ${ }^{5}$ The contribution of magnetic field towards the maximization of fusion power output is also limited by the fact that the magnetic field in the vicinity of a tokamak plasma is much lower than that attainable at the surface of the superconducting coil, thus:

$$
B_{\text {plasma }}=B_{\text {coil }}\left\{1-\left[\frac{\left(1+\frac{\Delta}{a}\right)}{A}\right]\right\} \text {. }
$$

Here the aspect ratio, $A$, is the ratio of the plasma major radius, $R$, to the plasma minor radius, a, while $\Delta$ is the space which must exist between the inner edge of. the plasma and the inner edge of the toroidal field coil in a reactor to accommodate structure, shleldiug and blankcts. since $\Delta / a$ is approximately equal to unity, plasmas of small aspect ratio make very inefficient use of the available magnetic field, and their power output when magnetically confined is drastically reduced.

The $\beta$-dependence in Equation (1) could be used to regain some of this lost power if we were able to operate plasmas at high values of $\beta$. However, the attainable $\beta$ in a given plasma is limited by equilibrium and stability considerations. In the low-beta ohmically-heated tokamaks which have been operated to date, the total $\beta$ can be written as

$$
B=\frac{\beta p}{q^{2} A^{2}} \text {, }
$$


where $B_{p}$ is the ratio of the plasma pressure to the magnetic field produced by the ohmic heating current; $q$ is the magnetic safety factor which is limited by the occurrence of kink instabilities. This relationship indicates that in order to attain the maximum value of $B$, tokamaks should be designed with very low aspect ratio. Thus, by comparing Equations (2) and (3), one can see that lowering the aspect ratio raises the $\beta$ but lowers the effective field, and therefore does not raise the power density significantly.

The remaining factors in Equation (3), $\beta_{p}$ and $q$, are determined by the stability of the plasma. Experiments have shown that for $q$ values of $<5$ there is a gradual deterioration in the quality of the plasma's energy containment and that the plasma is totally destroyed when $q$ is $<\sim 2.5$, due to a form of kink instability. ${ }^{6}$. On the other hand, the attainable values of $\beta_{p}$ have not been verified experimentally for the simple reason that ohmically heated tokamaks are only capable of reaching values of $\beta_{p}<1$. In the EPR design studies $2,3,4$ use has been made of two theoretically predicted limits on the value of $\beta_{p}$.

The first of these limits is related to the appearance of a magnetic separatrix on the inner side of a high-beta plasma when the tendency toward expansion in major radius is counteracted by the application of a uniform vertical field. A calculation of this effect indicates that $B_{p}$ is limited to values $<A .7$ A more sophisticated calculation is based on the shrinkage of the ohmic heating current profile due to the inward shrinkage of trapped particles (the so-called ware pinch effect). 8 This leads to a violation of the Kruskal-Shafranov condition on the axis of the plasma and restricts $B_{p}$ to values $<\sqrt{A} .^{9}$ Thus, the attainable $B$ in these EPR designs is $43 \%$.

In one of the EPR design studies ${ }^{3}$ use has been made of the noncircular plasma concept, whereby the effective aspect ratio of the plasma is extended by elongating the plasma cross section in parallel to the axis of the torus. In principle this allows Equation (3) to be modified thus: 


$$
\begin{gathered}
4 \\
B=\frac{B}{q^{2} A^{2}} c^{2},
\end{gathered}
$$

where $C$ is a measure of the plasma elongation. Clearly if $C$ can be equal to 2 or 3 , the attainable $\beta$ increases significantly. However, one faces significant economic and practical difficulties in attempting to implement this noncircular plasma concept. Stability calculations ${ }^{10}$ have indicated that the minimum acceptable value of the magnetic safety factor $q$ is larger in a noncircular device than in a circular device, a fact which offsets the advantage of the noncircular shape. Furthermore, the coils required to force the plasma into the noncircular shape are complicated and must be placed in inconvenient locations within the toroidal field coil, thus increasing the cost of the overall system. It-seems unlikely that gains in $\beta$ of more than a factor of 2 can be realized by this technique. 11

The above considerations have led to EPR designs with low aspect ratio. Once an aspect ratio has been chosen, the magnetic field in the plasma is determined by the maximum allowable field at the conductor. Thus there is strong motivation to utilize the more expensive high-field superconductors. The use of high field superconducting magnets in a low aspect-ratio torus iesults. in extreme asymmetric forces on the coils, which must be minimized by the fabrication of asymmetric coils. The problem of fabricating these asymmetric coils is further compounded by the criterion of large coil size established by the EPR designs.

\section{The Role of Energy Containment}

The size of the EPR plasma and its blanket and shield determines the size of the superconducting coil. The plasma size is determined by the scaling laws used to specify the energy containment of the plasma. All of the FPR designs have used the so-called trapped-ion mode scaling ${ }^{12}$ to specify the energy containment time. This is obtained from a crude nonlinear estimate of the saturated amplitude of a theoretlcally predicted plasma instability.

$$
n \tau=3.2 \times 10^{16}\left(\frac{\left(1 / 10^{6}\right)^{4}\left(B_{T} / 5\right)^{2} B_{p e}^{2} z_{\text {eff }}(A / 3)^{5 / 2}}{T_{\mathrm{keV}}^{11 / 2}}\right) .
$$


Because of the dependence on $\beta_{p e}$ indicated in this equation, a low $\beta_{p}$ reactor would need to be extremely large in order to attain an nt near the ignition condition. This large plasma size, combined with the necessity for a blanket and shield between the plasma and the superconducting coils, has resulted in EPR superconducting coil sizes of roughly $8 \times 12 \mathrm{~m}$ (horizontal and vertical dimension) weighing several hundred tons apiece. The low aspect ratio forced upon us by our desire to maximize the value of $\beta$ clearly aggravates the problem of plasma size, since it is the existence of trapped particles produced by the low aspect-ratio toroidal magnetic field that provides the mechanism for the predicted instability which results in the scaling law of Equation (5).

The trapped-particle scaling law also has a serious effect on the amount of peripheral equipment necessary to operate a fusion reactor. Obviously the $n t$ predicted by Equation (5) would be improved if higher $\beta_{\text {pe }}$ could be attained. However, in order to produce high values of the electron poloidal beta, power must be supplied to raise the plasma temperature and sustain its density. Because of the power losses in a system dominated by a trapped-ion mode, large amounts of pulsed power are required to drive the reactor to its ignition condition. It is possible in principle to reach the ignition condition in a smaller device, i.e., lower current in Equation (5). This is achieved by increasing the value of $R_{\text {pe }}$ at which the plasma opcrates. llowever, this optlon is ruled out by the assumed limit of $\beta_{p e}<1$.

\section{Additional Constraints}

Analysis of thermal cycling effects and techniques of remote maintenance and assembly of the toroidal blanket and shield structure in a low aspectratio EPR has revealed great practical difficulties, which could be alleviated by increasing the aspect ratio.

A general listing of the problems encountered in the EPR designs produced to date is as follows: 13 
1. Inherently unmanageable shape (low aspect ratio);

2. Pulsed operation;

3. Exacting tolerances on very large components;

4. Radiation damage requiring replacement of internals by totally remote means;

5. Very low inherent power density;

6. Very large electric power demands;

7. Excessively complex auxiliaries; and

8. Questionable breeding potential.

Many of these difficulties result from the plasma physics scaling laws and $\beta$ relationships discussed above. If one were able to increase the power density and the aspect ratio, most of these problems could be solved. The reason that this has not been done in the existing EPR designs is that trapped ion scaling [see Equation (5)] has dictated so large and expensive a machine that any increase made in major radius in order to increase the aspect ratio would render the EPR too expensive to construct.

\section{THE ROLE OF TNS}

TNS should be a device which represents a major step forward in the development of fusion power. It should also be a feasible step with respect to its technological complexity and cost. Finally and most fundamentally, it must be a step along the path to a realistic powerproducing fusion reactor. In order to fulfill these requirements, the TNS must avoid the problems which plague the EPR described in the reference designs. From the above discussion, it should be clear that these problems stem from the constraints which were believed to exist on the attainable plasma beta and the constraints which were projected for the energy containment time. In recent months two advances have been made which modify our view of the nature of these constraints. 
The Impact of Experimental Scaling Laws

In the first place, recent experimental results from the Massachusetts Institute of Technology (MIT) Alcator device ${ }^{14}$ have indicated that the empirical scaling law which describes the electron energy containment time in tokamaks can be extended by one order of magnitude. The energy containment time scaling shown in the following equation predicts very optimistic performance for tokamak devices which can operate in the physical regime to which the scaling law applies:

$$
n \tau_{e}=6.4 \times 10^{-19} a^{2} n^{2}
$$

In fact a recent proposal has appeared to construct a collisional fusion reactor based on this scaling law. ${ }^{15}$ The fundamental argument on which this collisional tokamak reactor was based is as follows. If the density can be raised to sufficiently high levels as we heat tokamak plasmas toward the ignition condition, the collisionality of the plasma, which is believed to determine the energy loss mechanism, could be maintained at a value equal to that of present-day experiments. Consequently, the scaling law for electron energy containment time shown in Equation (6) would apply. Unfortunately, if density and temperature are raised simultaneously, the resulting pressure of the plasma is quite large. The authors of Reference 12 attempted to provide for this high pressure by using extreme plasma elongations (Equation 4) and extremely high magnetic fields. For the reasons given above in our discussion of the EPR neither of these techniques seems particularly attractive. In addition, there is no known method of heating plasmas which are dense enough to maintain present-day collisionality in the reactor temperature regime.

However, an interesting argument has been advanced by $B$. Kadomtsev ${ }^{16}$ that if one can maintain the dimensionless parameters, such as collisionality, which determine the nature of the physical processes occurring in plasmas, at values close to those attained in present-day experiments one can with some confidence project the behavior of reactor-grade plasmas. 
We shall see that an extremely attractive TNS machine can be specified whose collisionality differs by less than one order of magnitude from present-day experimental collisionalities. Consequently, we might expect to be able to use the scaling law shown in Equation (6) to describe the electron energy containment in TNS.

Recent experimental results on the ORMAK device have provided us with additional information about the behavior of the plasma in TNS. Firstly, neutral injection heating has been shown to be capable of raising the plasma ion temperature to values in excess of the electron temperature. Furthermore, the ion energy containment time was shown to be consistent with neoclassical ion heat conductivity, which in a reactor provides the ion energy containment time scaling.

$$
n \tau_{i}=\frac{3 \times 10^{11} a^{7}\left(B_{T} / 5\right)^{2} T^{1 / 2}}{q^{2}(A / 3)^{3 / 2}} .
$$

Thus, over an extremely wide range of experimental parameters, empirical electron scaling and neoclassical ion heat conductivity describe the results of the present generation of experimental tokamaks.

In addition to verification of the ion temperature scaling in a new regime of operation, the ORMAK experiments have indicated that highdensity plasma operation, on which we base our expectation for the continued validity of Equation (6), can be produced and sustained by the same neutral injection heating which produced the record ion temperatures. Thus, we have some indication that the high densities required for nearcollisional operation of a TNS reactor-grade plasma can, in fact, be produced by available technology.

Figure 1 shows the $n \tau$ versus $T i$ plots for a possible TNS configuration using the scaling laws given by Equations (6) and (7). It is clear that these scaling laws allow the Ignition condition to be reached in a moderate size plasma. This performance can be increased still further by the application of moderate plasma elongation and the use of higher magnetic fields made possible by the weak aspect-ratio dependence of the 
scaling laws. Because the TNS device as shown attains quite high operating temperatures, and because the validity of the scaling law in Equation (6) improves with high density, the TNS is inherently a high-beta device and we must consider the applicable beta limits on such a device.

\section{The Impact of Relaxed $\beta$ Limits}

The second major advancement in recent months has been the recognition that the previously established limitations on the operating beta of a tokamak device are somewhat artificial. This follows from the fact that in a large hot tokamak, such as TNS, the time necessary for changes in internal magnetic fields to occur is $>100$ seconds, whereas the time necessary to heat the plasma is on the order of several seconds. Thus, as noted by clarke, ${ }^{17}$ the high beta plasmas produced in such devices by neutral injection evolve from low-beta equilibria in a flux-conserving manner, and have different equilibrium and stability characteristics from the high-beta equilibria which have been traditionally computed for tokamaks. The detailed consequences of this circumstance have been computed by clarke, et al.; 18 and Dory, Peng, and Marcus. 19 Stated simply, the overall results of these calculations is that in a flux-conserving tokamak there does not appear to be an equilibrium beta limit at all and one must look to MHD stability theory to provide a stabllity limit.

The nonapplicability of the two beta limits previously quoted follows immediately from flux conservatlon. Flux-conserving tokamak equilibria as computed by Dory, Peng, and Marcus ${ }^{19}$ are not supported against major radius expansion by a uniform vertical field as was the case in the simple calculation of Shafranov, ${ }^{8}$ so that no separatrix appears as the beta is raised. Flux conservation also results in a freezing of the q profile as the plasma beta is raised. Consequently, the bootstrap current effect does not produce a violation of the Kruskal-Shafranov ${ }^{9}$ limit on a time scale of experimental interest.

The beta relation in Equation (3) is only valid for high aspect-ratio low-beta tokamaks. For high-beta tokamaks the correct expression for 


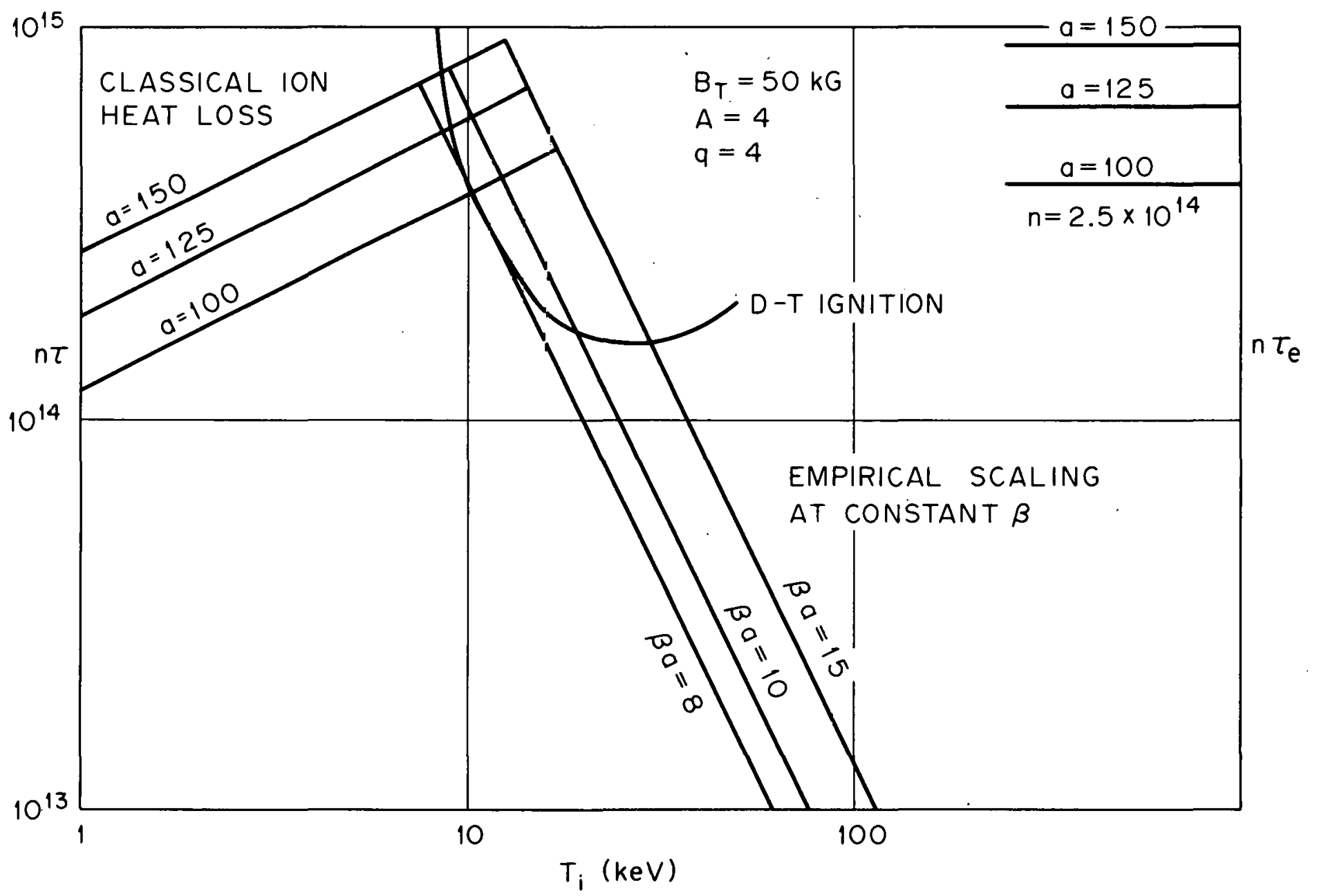

Fig. 1. This figure shows the nt which could be obtained in a typical TNS device of minor radius, a, using classical ion heat conductivity loss and the empirical electron energy containment scaling. Since the empirical electron scaling is independent of ion temperature, the horizontal lines on the right abscissa indicate the $n \tau$ which would be obtained at a fixed density of $2.5 \times 10^{14}$ particles per cubic centimeter. The diagonal lines labeled with the product of total beta and minor radius indicate the empirical scaling behavior at constant beta. Feedback control on the plasme density should allow the attainment of a stable operating point for the 100 centimeter device in the vicinity of $25 \mathrm{kV}$ at a beta of $10 \%$. 
beta is given in the following equation, which reduces to Equation (3) in the limit of low beta and large aspect ratio:

$$
\beta=\beta_{P} \frac{\left\langle B_{P}^{2}\right\rangle}{B_{T}^{2}} \ldots
$$

Calculations 17,18,19 which describe the behavior of a flux-conserving tokamak indicate that as the plasma pressure is raised, the expression in Equation ( 8 ) continues to increase above the low beta limit set by Equation (3).

Application to TNS

Point model calculations of the dynamics of a one-meter plasma radius $T_{N S}{ }^{21}$ indicate that ignition condition can be obtained with as little as $25 \mathrm{MW}$ of injected power applied for roughly five seconds. It may easily be verified from the data shown in Figure 1 that such a device would produce on the order of $150 \mathrm{MW}$ of thermal fusion power at ignition. Thus, one could expect such a device to achieve real energy break-even with as little as a two-second burn; and if the device were able to sustain its high beta equilibrium for a magnetic skin time, it would produce an energy gain of $>50$. Admittedly these are optimistic numbers, but the obvious improvements over the previous reactor concepts embodied in the existing EPR design should be evident.

The advantages of operating at the high values of $\beta_{\text {pe }}$ permitted in a flux conservation tokamak are also evident if the behavior of TNS is analyzed using the trapped ion scaling of Equation (5). Because of the dependence on $\beta_{p e}^{2}$ the $n \tau$ obtained from this scaling is substantially the same as the empirical scaling law. Therefore even if the empirical scaling laws observed in today's collisional experiments are the result of insipient trapped particle modes, an ignition condition should be attainable in a moderate size TNS if the $\beta_{\text {pe }}$ can in fact be raised by auxiliary heating.

*Symbols defined in Reference 20. 
A systematic treatment of the behavior of such a device, including a thorough assessment of the engineering advantages to be gained by operation at high aspect ratio and the MHD stability limits on beta, has yet to be performed. The worth of such an analysis is obvious, since preliminary analysis reveals that a device embodying the scaling laws and fluxconserving principles outlined above satisfies the three requirements for a TNS facility. It would be a major step forward in the development of fusion power since it represents the attainment of the ignition condition. It possesses characteristics that make it a feasible step in terms of its technological complexity and cost, since it is compatible with superconducting magnet technology which we fully expect to have available by 1979 , and since it is roughly half the size of the previously-considered EPR and requires far less peripheral equipment, such as neutral beam injectors. Finally and most fundamentally, it is a significant step along the path to a realistic power-producing fusion reactor. 


\section{REFERENCES}

1. P. N. Haubenreich (Ed.), Description of a Reference Design Tokamak for the Technology Test Assembly, ORNL/TM-4820, October 1975.

2. M. Roberts and E. S. Bettis, Oak Ridge Tokamak Experimental Power Reactor Study Reference Design, ORNL/TM-5042, November 1975.

3. GAC Fusion Engineering Staff, Experimental Power Reactor Conceptual Design Study, GA-A13534, prepared for Electric Power Research Institute, July 1975.

4. W. M. Stacey et al., Tokamak Experimental Power Reactor Studies, ANL/CTR-75-2, June 1975.

5. M. Roberts, private communication, January 1976.

6. ORMAK Upgrade: A Proposed Tokamak Device for Plasma Heating and Stability Investigations, ORNL/TM-5130 (to be published).

7. V. S. Mukhovatov and V. D. Shafranov, Plasma Equilibrium in a Tokamak, Nuclear Fusion 11, 605-633 (1971).

8. A. Ware, Phys. Rev. Letter (1970).

9. A. A. Galeev and R. Z. Sagdeev, Vopr. Teor, Plazmy 7, 205 (1973).

10. a) J. P. Freidberg and W. Grossmann, Magnetohydrodynamic Stability of a Sharp Boundary Model of Tokamak, Phys. Fluids 18, 1494 (1975).

b) Y-K. M. Peng et al., Magnetodydrodynamic Stabillty of Axisymmetric Tokamak Equilibria, ORNL/TM-5267 (to be published).

11. H. K. Forsen et al., Report of The Ad Hoc Panel on Configurational Optimization and Impurity Control in Tokamaks, ERDA-6, June 1974.

12. S. Dean et al., Status and Objectives of Tokamak Systems for Fusion Research, WASH-1295 (1973).

13. E. S. Bettis, private communication, November 1975.

14. R. Parker, private communication, November 1975.

15. D. R. Conn. D. L. Jassby, and R. R. Parker, Prospects of Thermonuclear Ignition in a "Collisional" Tokamak, MATT-1170, Princeton Plasma Physics Laboratory, October 1975.

16. B. Kadomtsev, Fizika Plazmy I (4), 531-535 (1975).

17. J. F. Clarke, Accessibility of High Beta Equilibria in Tokamaks, Bull. Amer. Phys. Sne. 20, 1228 (1975). 
18. J. F. Clarke, D. J. Sigmar, R. A. Dory, and Y-K. M. Peng, Flux Conserving High Beta Toroidal Equilibria, paper presented at Annual Meeting on Theoretical Aspects of CTR, April 7-9, 1976, Madison, Wisconsin (to be published in Phys. Rev. Letters).

19. R. A. Dory, Y-K. M. Peng, and F. B. Marcus, Flux-Conserving Equilibria for Tokamaks, Theory Department Memo 76/29, ORNL, March 22, 1976.

20. J. D. Callen and R. A. Dory, Magnetohydrodynamic Equilibria in Sharply Curved Axisymmetric Devices, Phys. Fluids 15, 1523 (1972).

21. D. G. McAlees, private communication, March 18, 1976. 
Internal Distribution

ORNL/TM-5418

$\begin{aligned} \text { 1. } & \text { L. A. Berry } \\ \text { 2. } & \text { J. D. Callen } \\ \text { 3-12. } & \text { J. F. Clarke } \\ \text { 13. } & \text { F. L. Culler } \\ \text { 14. } & \text { R. A. Dandl } \\ \text { 15. } & \text { C. A. Flanagan } \\ \text { 16. } & \text { P. N. Haubenreich } \\ \text { 17. } & \text { G. G. Kelley } \\ \text { 18. } & \text { H. M. Long } \\ \text { 19. } & \text { O. B. Morgan } \\ \text { 20. } & \text { H. Postma }\end{aligned}$

21. M. Roberts

22. M. W. Rosenthal

23. D. Steiner

24. L. D. Stewart

25-26. Central Research Library

27. Document Reference Section

28. ORNL Patent Office

29. Laboratory Records, RC

30-31. Laboratory Records

32. Thermonuclear Division Library

33. CTR Reports Office

\section{External Distribution}

34. Director, Division of Research and Technical Support, USERDA-ORO

35. D. J. Anthony, General Electric Company, Energy Systems and Technical Division, I River Road, Schenectady, NY 12345

36. S. J. Buchsbaum, Executive Director, Research Communications Science Division, Bell Laboratory, Crawford Corner Road, Holmdel, NJ 07733

37. R. W. Bussard, 462 Santa Cecelia, Solana Beach, CA 92075

38. A. T. Christensen, Manager, Program Development, General Electric Company, 777 14th Street, N.W., Washington, DC 20005

39. R. W. Conn, Department of Nuclear Engineering, University of Wisconsin, Madison; WI 53706

40. E. C. Creutz, Assistant Director for Research, National Science Foundation, 1800 G. Street; N.W., Washington, DC 20550

41. S. 0. Dean, Assistant Director for Confinement Systems, Division of Controlled Thermonuclear Research, USERDA, Mail Station G-234, Washington, DC 20545

42. S. Fernbach, Lawrence Livermore Laboratory, University of California, P. 0. Box 808, Livermore, CA 94551

43. T. K. Fowler, Associate Director, Lawrence Livermore Laboratory, University of California, P. 0. Box 808, Livermore, CA 94551

44. H. P. Furth, Co-Head Experimental Division, Plasma Physics Laboratory, Princeton University, P. 0. Box 451, Princeton, NJ 08540

45. F. C. Gilbert, Division of Military Application, USERDA, Washington, DC 20545

46. M. B. Gottlieh, Director, Plasma Physics Laboratory, Princeton University, P. 0. Box 451, Princeton, NJ 08540

47. W. C. Gough, Electric Power Research Institute, 3412 Hillview Avenue, P. 0. Box 10412, Palo Alto, CA 94304

48. R. W. Gould, Department of Applied Physics, California Institute of Technology, Pasadena, CA 91109

49. J. N. Grace, Technical Project Officer, Division of Controlled Thermonuclear Research, USERDA, Mail Station G-234, Washington, DC 20545 
50. H. Grad, Courant Institute, New York University, 251 Mercer Street, New York, NY 10012

51. G. K. Hess, Jr., Senior Scientific Advisor, Division of Controlled Thermonuclear Research, USERDA, Mail Station G-234, Washington, DC 20545

52. R. L. Hirsch, Director, Division of Controlled Thermonuclear Research, USERDA, Mail Station G-234, Washington, DC 20545

53. E. S. Keen, Boeing Company, 102 Tulsa Road, Oak Ridge, TN 37830

54. E. E. Kintner, Deputy Director, Division of Controlled Thermonuclear Research, USERDA, Mail Station G-234, Washington, DC 20545

55. B. Miller, Assistant Director for Research, Division of Controlled Thermonuclear Research, USERDA, Mail Station G-234, Washington, DC 20545

56. T. Ohkawa, General Atomic Company, P. 0. Box 81608, San Diego, CA 92212

57. P. J. Reardon, Head of Tokamak Fusion Test Reactor, Plasma Physics Laboratory, Princeton University, P. 0. Box 451 , Princeton, NJ 08540

58. F. L. Ribe, Division Leader, CTR Division, Los Alamos Scientific Laboratory, P. 0. Box 1663, Los Alamos, NM 87544

59. D. J. Rose, Department of Nuclear Engineering, Massachusetts Institute of Technology, Cambridge, MA 02139

60. Z. Shapiro, Executive Assistant to the General Manager, Breeder Reactor Division, Westinghouse Electric Corporation, P. O. Box 355, Pittsburgh, PA 15230

61. A. Trivelpiece, Department of Physics \& Astronomy, University of Maryland, College Park, MD 20742

62. H. H. Woodson, Chairman, Department of Electrical Engineering, The University of Texas at Austin, Austin, TX 78712

63-89. Technical Information Cencer, USERDA 